\title{
OS DIREITOS HUMANOS E SUA EFICÁCIA NAS RELAÇÕES PRIVADAS
}

\section{Carlos Eduardo do Nascimento ${ }^{1}$ Lucas Coelho Nabut ${ }^{2}$}

\section{RESUMO}

O trabalho aborda a crise do liberalismo na pós-modernidade, os efeitos sofridos pelos institutos de direito privado em virtude da constitucionalização, razão pela qual se mostra intensa a necessidade dos Direitos Humanos, sempre colocados à disposição da proteção do indivíduo na relação entravada com o Estado, terem sua eficácia estendida também às relações particulares, restando demonstrada que a suposta isonomia entre as partes nas relações privadas não passava de uma hipótese doutrinária, a qual não se concretizou. Desta forma, será analisada a transformação dos clássicos princípios dos institutos e o surgimento de uma nova realidade, amparados nos direitos humanos.

Palavras chave: constitucionalização; direitos humanos; relações privadas; eficácia; nova realidade.

\section{THE HUMAN RIGHTS AND THEIR EFFECTIVENESS IN PRIVATE RELATIONS}

\section{ABSTRACT}

The work addresses the crisis of liberalism in postmodernity, and the effects suffered by private law institutes because of their constitutionalisation, which is why it shows the intense need of human rights, always available to the protection of the individual in relation hampered with the state, have extended their effectiveness also in relations between individuals, which remained demonstrated that the alleged equality between the parties in private relationships was only a doctrinal hypothesis, which didn't materialize in society. Thus, the transformation of the classical principles of the institutes and the emergence of a new reality will be analyzed, supported on human rights.

Keywords: constitutionalization; human rights; private relationships; efficiency; new reality.

\section{Introdução}

O Estado Liberal se mostra como legado da Revolução Francesa, sob as luzes iluministas que cunharam as noções de subjetividade, e, com ela, a do individualismo, expressa na autonomia da vontade e liberdade de ação, acentuando ainda mais as diferenças

\footnotetext{
${ }^{1}$ Doutor em Direito Político e Econômico pela Universidade Presbiteriana Mackenzie, Advogado com experiência em Direito Público, Secretário Adjunto de Administração da Prefeitura Municipal de Uberaba, Professor de Cursos de Graduação e Pós Graduação, Avaliador de Cursos pelo INEP/MEC. Email: censo@terra.com.br

${ }^{2}$ Doutorando em Direito Político e Econômico pela Universidade Presbiteriana Mackenzie, Advogado, Professor de Cursos de Graduação e Pós Graduação. Email: lucas@bnradvogados.com.br
} 
entre o público e o privado. Dogmas religiosos cederam lugar, na ciência, à racionalidade crítica e, na política, às liberdades individuais e aos direitos de todo cidadão, onde os direitos individuais eram consagrados como absolutos.

Cultuava-se a ideia da liberdade puramente formal, sob a influência do primado da lei, que prescreve comportamentos gerais e abstratos obrigatórios para todos. Neste contexto, institucionaliza-se a clássica dicotomia entre público e privado, não autorizando o Estado a interferir na zona de liberdade individual dos particulares, sob qualquer pretexto. Os conceitos clássicos dos institutos de direito privado, como o contrato e a propriedade, não mais se adaptavam à realidade socioeconômica do séc. XX.

Porém, tal estrutura ruiu na medida em que o Estado passou a ter como objetivo a tutela jurídica daquele vulnerável em determinada relação, assumindo um papel mais social, fenômeno este surgido após a Revolução Industrial e a consequente massificação das relações contratuais.

A intervenção estatal sobre as relações jurídico- privadas, com a fixação de normas que submeteram a contratação a parâmetros delimitados pelo Poder Público, é justificada por Lisboa (2007, p. 27) pelo desenvolvimento tecnológico e crescimento demográfico mundial, aliados à concentração das riquezas nas mãos de poucos e, por vezes, ao correspondente empobrecimento da maioria das pessoas, procurando assim a minoração das diferenças socioeconômicas, tentando promover o reequilíbrio contratual.

A partir destes fenômenos, o esforço interpretativo da doutrina detectou a necessidade de uma releitura de conceitos e institutos clássicos, elaboração e desenvolvimento de novas categorias jurídicas e interação estreita entre diferentes campos da ciência jurídica (superação da velha dicotomia clássica de direito público e privado).

Nessa perspectiva, tratará a pesquisa proposta da busca da função social nos institutos clássicos do direito civil e de sua eventual conformação ao regime jurídico econômico brasileiro e dos direitos fundamentais, no âmbito do Estado Democrático de Direito.

Busca-se, assim, analisar os institutos jurídicos privados à luz do conjunto sistematizado de princípios e normas que devem ser observados.

Assim, a partir da constitucionalização do direito privado, o presente trabalho tem como tema a relação dos direitos fundamentais constitucionais, principalmente o princípio da dignidade da pessoa humana, com o direito privado, atuando como meios de dirigismo. 


\section{Breves apontamentos acerca dos direitos humanos}

Muito embora empregados indistintamente diversas expressões, como direitos naturais, direitos humanos, direitos individuais, direitos do homem, direitos públicos subjetivos, liberdades fundamentais, liberdades públicas e direitos fundamentais, preferimos a denominação direitos humanos.

Conforme definição de Tavares (2008, p. 425), os direitos humanos serão aqueles essenciais, sem os quais não se reconhece o conceito estabelecido de vida. Não há uma relação estabelecida e final de tais direitos, já que seu caráter é progressivo, correspondendo a cada momento ao estágio cultural da civilização.

A doutrina dos direitos humanos, concebida a partir do século passado, engendrou mecanismos de proteção do individuo em face do Estado. As garantias fundamentais concebidas pelo direito público, afastando as ingerências do Estado da esfera privada. Hannah Arendt realça, a partir dos problemas jurídicos suscitados pelo totalitarismo, que o primeiro direito humano é o direito a ter direitos (LAFER, 1988, p. 154).

Numa visão contemporânea, encontramos os direitos humanos fundados na universalidade e na indivisibilidade. Piovesan (2003, p. 226) explica o caráter universal, uma vez que a condição de pessoa há de ser o requisito único para a titularidade de direitos, afastada qualquer outra condição. Dessa forma, a asserção dos direitos humanos se dá independentemente do status civitatis (LAFER, 1988, p. 146).

Mesmo com esse caráter universal, podemos encontrar alguns direitos fundamentais inerentes a apenas determinadas pessoas, como por exemplo a ação popular e os direitos políticos em geral, os quais são titularizados apenas por aquelas pessoas qualificadas como cidadãos.

Já a indivisibilidade refere-se aos direitos civis e políticos deverem ser somados aos direitos sociais, econômicos e culturais.

Durante o longo e tormentoso processo de consolidação dos instrumentos de proteção dos direitos humanos, que no âmbito do direito internacional, mediante celebração de tratados e convenções, quer no plano interno, no que concerne aos textos constitucionais e 
às declarações de direitos fundamentais, a matéria manteve-se essencialmente contida nas balizas do direito público (TEPEDINO, 2006, p. 64).

Porém, ao atestar a insuficiência do paradigma liberal- individualista, a Carta de 1988, busca responder à emergência de um novo padrão de conflituosidade, bem como à exigência de novos direitos fundamentais (PIOVESAN, 2003, p. 225).

Desta forma, podemos afirmar que os refinados instrumentos de proteção dos direitos humanos, postos à disposição pelo direito público, poderiam se efetivar caso as políticas públicas e a atividade econômica privada escaparem aos mecanismos de controle jurídico, evitando a exclusão social e o desrespeito à dignidade da pessoa humana.

\section{A constitucionalização do direito privado}

O sistema individualista, consagrado na Revolução Francesa, bem como no Código Napoleônico, o qual serviu de base para todo o direito privado pátrio, tendo como cerne do direito privado a liberdade de vontade e a propriedade, elementos estes absolutos, não mais atendiam as necessidades de regular as relações socioeconômicas surgidas após a Revolução Industrial.

A liberdade de contratar e o direito de propriedade eram o cerne do direito privado, ao longo do século XX esse quadro se alterou, com a progressiva superação do liberalismo puro pelo intervencionismo estatal. A proliferação de normas cogentes, indisponíveis pelos contratantes, assinala a publicização do direito privado.

Assim surge o dirigismo contratual, que significa a intervenção do Estado na economia dos contratos, em virtude da supremacia do interesse público sobre o particular. Como consequência, a autonomia das vontades começa a ficar limitada por normas de ordem pública, as quais não podem ser afastadas por vontade das partes do contrato. Tal dirigismo visa unicamente a proteção da parte vulnerável da relação e o reequilíbrio das posições contratuais.

Mesmo com tal intervenção estatal, nitidamente definida ainda estava a separação entre o direito público e o direito privado, principalmente para os doutrinadores deste ramo do direito, pois, conforme lição de PEREIRA (2004, p. 14):

Os princípios de ordem pública não chegam a constituir direito público, por faltar a participação do estatal na relação criada, que se estabelece toda entre particulares. 
São, pois, princípios de direito privado. Mas, tendo em vista a natureza especial da tutela jurídica e a finalidade social do interesse em jogo, compõem uma categoria de princípios que regem relações entre particulares, a que o Estado dá maior relevo em razão do interesse público em jogo. São, pois, princípios de direito privado que atuam na tutela do bem coletivo, inderrogáveis pela vontade das partes...

Já mais próximo da virada do século, esse processo se aprofunda, dando lugar a um novo desenvolvimento dogmático, referido pela doutrina como constitucionalização do direito civil.

Inegável que sempre a Constituição foi considerada como norma suprema do sistema jurídico. Porém, o direito constitucional se restringia a cuidar da organização política e administrativa do Estado, relegando para o Código Civil a tarefa de disciplinar as relações privadas.

A constitucionalização do direito civil, ou a constitucionalização do direito privado como preferem alguns, teve sua origem em nosso país apenas com a Constituição de 1988, a qual impôs uma releitura dos institutos fundamentais do direito civil.

A partir de então, a Constituição passou a desfrutar não somente da supremacia formal, mas também de uma supremacia material, axiológica, potencializada pela abertura do sistema jurídico e pela normatividade de seus princípios (BARROSO, 2009, p. 150).

Com base na afirmação realizada no parágrafo acima, podemos observar que a constitucionalização do direito privado só se mostrou possível graças à superação do positivismo, onde os princípios eram considerados meros mandamentos na busca de determinado fim, sem qualquer eficácia normativa, ao contrário do que hoje já é reconhecido pelo pós- positivismo.

Esse fenômeno da constitucionalização pode ser definido como a sujeição das normas e institutos do direito civil aos princípios e regras constitucionais. De fasto, valores constitucionais como dignidade da pessoa humana, solidariedade social e igualdade substancial marcam decisivamente a mudança do direito civil contemporâneo.

O Código Civil, sempre considerado como a constituição das relações particulares, perde definitivamente o seu papel central no âmbito do próprio setor privado, cedendo passo para a crescente influencia da Constituição. Os princípios constitucionais passam a condicionar a própria leitura e interpretação dos institutos de direito privado.

A ideia de constitucionalização do direito está associada a um efeito expansivo das normas constitucionais. Limita a autonomia de vontade dos particulares, em domínios como a 
liberdade de contratar ou o uso da propriedade privada, subordinando-os a valores constitucionais.

Nesse quadro, surge a chamada filtragem constitucional, identificada por alguns autores como o fenômeno em que toda ordem jurídica deve ser lida e aprendida sob a lente da Constituição, de modo a realizar os valores nela consagrados. Em nossas aulas de direito civil utilizamos a metáfora de que, ao lermos o Código Civil, a luz que ilumina essa leitura deve ser a Constituição Federal.

Assim, conforme exposto por Barroso (2009, p. 152), a Constituição Federal é o vetor de interpretação de todas as normas do sistema, e a constitucionalização nada mais é do que a reinterpretação de institutos privados já existentes, utilizando-se o método ora explanado.

Com essa nova interpretação, a dignidade da pessoa humana assume sua dimensão transcendental e normativa (BARROSO, 2007, p. 59), ou seja, enseja a despatrimonialização e personalização do direito civil. O patrimônio, que sempre foi o cerne das relações privadas, cede lugar à pessoa, a qual se torna o centro de todo o nosso ordenamento.

A tutela das relações jurídicas deve dar prevalência aos sujeitos desta relação, sempre objetivando a dignidade dessas pessoas, e não mais ao patrimônio como ocorria anteriormente. Pode-se falar portanto, que o direito civil não mais é patrimonializado, mas sim personalizado, tendo como principal finalidade a dignidade da pessoa humana, tema este que será abordado no decorrer desse trabalho.

Nessa linha, por certo, a necessária promoção dos valores e princípios constitucionais no âmbito das relações privadas, tem o condão de propiciar proteção a grupos minoritários.

A partir da personalização do direito, originada da sua constitucionalização, encontramos três consequências principais:

i. uma releitura de conceitos e institutos clássicos, como os contratos e a propriedade, tendo a autonomia do titular perdido seu caráter absoluto.

$i$. elaboração e desenvolvimento de novas categorias jurídicas, podendo ser citado como exemplo o reconhecimento das uniões homoafetivas.

ii. interação estreita entre diferentes campos da ciência jurídica (superação da velha dicotomia clássica de direito público e privado). 
Mais uma vez é necessário ressaltar, que, assim como na fase da publicização do privado, não que os institutos de direito civil tenham passado a constituir matéria de direito público, mas sim, porque ganharam, em sua essência, uma regulamentação fundamental em sede constitucional, muito embora tenha havido o surgimento de laços muito mais estreitos entre o direito público e o privado, e sua linha divisória tenha ficado muito mais tênue.

Neste ponto, a constitucionalização do direito civil pode se traduzir em três fases. A primeira consistente em mundos apartados, ou seja, no início do constitucionalismo moderno a constituição servia apenas à regular as relações entre o Estado e o cidadão, ao passo que o Código Civil era o documento jurídico que regia as relações entre particulares.

Uma segunda fase consistente na publicização do direito privado, surgindo ao longo do séc. XX, com o advento do Estado social. É a fase do dirigismo contratual. E por fim, a fase da constitucionalização do direito civil.

Consideramos que a constitucionalização do direito privado, muito embora não tenha tido suas raízes na publicização do direito privado, e estes dois fenômenos não se confundem, foi da publicização que tenha decorrido cronologicamente, e por certo, necessário reconhecer que sem a publicização anterior, muito dificilmente se estaria hoje falando em constitucionalização, pois o direito privado ainda estaria sendo considerado um dogma.

De forma mais didática impossível, Rosenvald (2010, p. 39) diferencia os dois fenômenos:

Por derradeiro, atente-se para a impossibilidade de confundir o chamado direito civil constitucional com outro movimento, designado publicização do direito civil. A constitucionalização não afetou a natureza privada da norma de direito civil. Todavia, é possível detectar ainda, na contemporaneidade jurídica, situações nas quais o legislador opta por publicizar relações jurídica basicamente privadas, através de uma interferência estatal, com o propósito de reequilibrá-la, eliminando desigualdades fáticas oriundas das diferentes posições das partes. Trata-se de um verdadeiro dirigismo contratual por parte do Poder Público. Desse modo, enquanto a constitucionalização do direito civil implica na migração das regras e princípios fundamentais do direito privado para sede constitucional, sem alterar a natureza privada da norma jurídica, a publicização do direito civil resulta de uma intergerência estatal em determinadas relações privadas, com o escopo de nivelar a posição entre as partes, evitando que a superioridade econômica de uma delas prejudique a outra e conferindo uma certa dose de caráter público a uma relação cuja natureza, originariamente, era estritamente privada.

Como vimos, muito bem vindos são os efeitos da constitucionalização na busca do bem comum e tutela da pessoa humana, bem como na superação das três principais preocupações do direito civil atual, identificadas por Tepedino (2006, p. 22) como as novas 
tecnologias e seus impactos na tutela da pessoa humana, a contratação em massa e as situações de vulnerabilidade e a proteção aos direitos fundamentais.

\section{A eficácia horizontal dos direitos fundamentais}

De forma bastante simplória, os direitos fundamentais visam limitar o poder estatal frente o cidadão. Assim, na relação entre Estado e cidadão, lá estão os direitos fundamentais impondo àquele um dever de abstenção, muito embora existam direitos fundamentais que impõem ao Poder Público um dever de prestação.

Conforme afirmado por Tavares (2006, p. 117), a expressão “direitos fundamentais" em muito se aproxima da noção de direitos naturais, no sentido de que a natureza humana seria portadora de certo número de direitos fundamentais. Desta forma, sabe-se que não há uma lista imutável dos direitos fundamentais, que variam no tempo.

Porém, grandes já foram as discussões acerca da eficácia ou não dos direitos fundamentais às relações privadas, a chamada eficácia horizontal dos direitos fundamentais.

De pouca serventia seriam os instrumentos de proteção dos direitos fundamentais, postos à disposição pelo direito público, se a atividade econômica privada escapar aos mecanismos de controle, incrementando a exclusão social e o desrespeito à dignidade da pessoa humana.

$\mathrm{Na}$ realidade brasileira, inúmeras hipóteses de agressão à pessoa humana foram registradas em face da insuficiência da legislação infraconstitucional, associada à timidez da magistratura em valer-se diretamente dos princípios fundamentais para a solução de conflitos na atividade privada. Como exemplo, Tepedino (2006, p. 48) nos trás a resistência da doutrina e jurisprudência, diante da ausência de regulamentação legal, em admitira intervenção cirúrgica de alteração do sexo, representando verdadeira agressão à dignidade da pessoa.

Nossa constituição nada dispõe a respeito da aplicabilidade dos direitos fundamentais às relações entre particulares, ao contrário da Constituição portuguesa, que expressamente prevê, em seu artigo $18^{\circ}$, que os preceitos consagradores de direitos, liberdades e garantias vinculam as entidades privadas, sugere-se, inequivocamente, o alargamento da eficácia desses direitos às relações entre particulares. 
Hodiernamente, a grande maioria dos autores que se dedicam ao tema está de acordo no reconhecimento da aplicação dos direitos fundamentais nas relações entre particulares, devendo porém, envolver uma ponderação de interesses, uma vez que neste caso, e ao contrário da relação Estado/ cidadão, ambos são titulares de direitos fundamentais.

Sarlet (2006, p. 382) defende a eficácia horizontal dos direitos fundamentais, inclinando-se em prol de uma necessária vinculação direta prima facie também dos particulares aos direitos fundamentais, sem deixar de reconhecer, todavia, na esteira de Canotilho e outros, que o modo pela qual se opera a aplicação dos direitos fundamentais às relações jurídicas entre particulares não é uniforme, reclamando soluções diferenciadas.

Nada mais necessário do que a adoção destas soluções diferenciadas, senão vejamos um exemplo hipotético de um pai que compra uma lembrança apara apenas um dos filhos. Aplicando os direitos fundamentais a esta relação particular, o pai lesou o direito da isonomia frente os demais filhos, o que não nos parece razoável.

Neste sentido Sarmento (2006, p. 326) leciona com perfeição:

\begin{abstract}
A incidência dos direitos fundamentais nas relações privadas é uma necessidade que poucos contestam. Todavia, a forma e a intensidade da vinculação dos particulares aos direitos fundamentais não pode ser idêntica à do Estado, já que os atores privados são também titulares de direitos fundamentais, e se beneficiam da proteção conferida à sua autonomia. A extensão incondicionada dos direitos fundamentais ao campo privado poderia gerar efeitos opostos aos pretendidos, revelando-se liberticida. A multiplicação de deveres constitucionais, correlatos aos direitos, asfixiaria a espontaneidade das relações humanas, confiscando da pessoa o espaço mínimo de autodeterminação de que é titular, o qual não deve ser ameaçado numa ordem constitucional demcrática, preocupada primordialmente com a garantia e a promoção da dignidade da pessoa humana.
\end{abstract}

O Supremo Tribunal Federal, por muitas vezes já decidiu em favor da eficácia horizontal dos direitos fundamentais, conforme a exemplar ementar do RE 201819/RJ, tendo como relatora a Ministra Ellen Gracie.

Mesmo que solucionada a discussão acerca da eficácia horizontal dos direitos fundamentais, certa controvérsia ainda persiste, pois conforme Canotilho (2003, p. 1287), a eficácia dos direitos fundamentais às relações entre particulares pode se dar de duas espécies de eficácia, a imediata e a mediata. Para a primeira, os direitos fundamentais tem uma eficácia absoluta nas relações particulares, aplicam-se direta e obrigatoriamente. Já para a segunda, a eficácia seria meramente indireta, pois vincularia primeiramente o legislador, que seria obrigado a observar os direitos fundamentais na elaboração das leis que regulam as 
relações privadas. Nessa linha, a eficácia dos direitos fundamentais estariam a depender da existência de leis infraconstitucionais.

Barroso (2009, p. 158) reconhece as duas correntes de eficácia mediata e imediata, onde a primeira se dá mediante atuação do legislador infraconstitucional e atribuição de sentido às cláusulas abertas, e a segunda, mediante um critério de ponderação entre os princípios constitucionais da livre iniciativa e da autonomia de vontade, de um lado, e o direito fundamental em jogo, do outro lado.

Concordamos com renomado constitucionalista no ponto de vista da aplicabilidade imediata afigurar-se mais adequada para a realidade brasileira e tem prevalecido na doutrina, e desta forma alguns critérios merecem relevo: a igualdade ou desigualdade material entre as partes, manifesta injustiça ou falta de razoabilidade do critério, preferência para valores existenciais sobre patrimoniais e risco para a dignidade da pessoa humana.

Porém, necessário ressaltar a advertência feita por Tavares (2006, p. 451), onde, com a eficácia direta e imediata corre-se o grave risco, especialmente no Brasil, de constitucionalizar todo o direito e todas as relações particulares, relegando o Direito privado a segundo plano no tratamento de tais matérias. O que resultaria na transformação do STF em verdadeira Corte de Revisão, porque todas as relações sociais passariam imediatamente a ser relações de índole constitucional, o que não é desejável.

Canotilho (2003, p. 1292) leciona ainda os deveres do Judiciário de aplicação dos direitos fundamentais no julgamento de lides entre particulares, quais sejam: fazer uma aplicação do direito privado em conformidade com os direitos fundamentais, pela via da interpretação conforme a constituição; reconhecimento da inconstitucionalidade da lei de direito privado que confrontar os direitos fundamentais; e concretização de bens jurídicos constitucionalmente protegidos, como a vida e a liberdade.

Outra questão bastante tormentosa, refere-se ao fato da Constituição fazer referencia expressa, em alguns poucos casos, à titularidade de direitos fundamentais por pessoa jurídica. Assim, para alguns autores, a titularidade dos direitos fundamentais estende-se às pessoas jurídicas, já para outros não.

Contudo, o Supremo Tribunal Federal já se manifestou no sentido de que alguns dos direitos do artigo 150 da Constituição constituem direitos fundamentais dos contribuintes, aplicáveis, é certo, às pessoas jurídicas quando sujeitos passivos da relação tributária. Assim, 
há de se admitir portanto, ainda que minimamente, a titularidade de direitos fundamentais pelas pessoas jurídicas.

Portanto, nos parece que o reconhecimento da eficácia dos direitos fundamentais às relações privadas, na forma imediata, é a que melhor atende os anseios dos princípios e fundamentos de nossa constituição, de forma a abreviar o caminho na busca da dignidade da pessoa humana dentro das relações entre particulares, pois, conforme as palavras de Sarmento (2006, p. 332): "Procuramos demonstrar que a aplicação dos direitos fundamentais deve ser ampliada para todas as esferas da vida humana, pois o poder e a opressão que ameaça, a dignidade da pessoa estão em toda parte".

A proteção dos direitos humanos não mais pode ser perseguida a contento se confinada no âmbito do direito público, sendo possível mesmo aduzir que as pressões do mercado, especialmente intensas na atividade econômica privada, podem favorecer uma conspícua violação à dignidade da pessoa humana. No campo das relações privadas, a usual técnica regulamentar mostra-se avessa à proteção dos direitos humanos, pois que incapaz de abranger todas as hipóteses em que a pessoa humana se encontra a exigir tutela.

\section{O princípio da dignidade da pessoa humana}

A Constituição Federal consagra o princípio da dignidade da pessoa humana como um dos fundamentos da República Federativa, nos termos do artigo $1^{\circ} \mathrm{m}$ inciso III, razão pela qual esse respeito à dignidade da pessoa humana deve orientar as relações em geral, de modo a submeter os demais princípios e normas, mesmo que constitucionais.

Segundo Nelson Rosenvald (2010, p. 08) “o significado de dignidade se relaciona ao respeito inerente a todo o ser humano - por parte do Estado e das demais pessoas independentemente de qualquer noção de patrimonialidade”.

Há controvérsia acerca do conteúdo do princípio da dignidade da pessoa humana. Conforme Reale (1996, p. 277), historicamente se apresentam três concepções acerca do princípio em questão, quais sejam, a individualista, a transpersonalista e a personalista, a depender do ponto de partida da qual se desenvolve, e assim dos valores humanos que pretende tutelar. Trata, contanto, de abranger: a) a esfera individual, sem preocupação com os direitos coletivos lato sensu; b) a esfera coletiva, que se supõe ao indivíduo; ou c) a esfera 
personalíssima do ser humano, mas que não se descuida dos preceitos éticos e morais que contribuem para a harmonia e convivência das pessoas em sociedade.

É nesse último contexto que se insere o princípio da dignidade da pessoa humana atualmente, funcionando, ainda, como limite à atuação do Estado, em sede de relação horizontal do poder que impõe ao cidadão, e do próprio indivíduo, no que tange as relações horizontais entre particulares. Ao mesmo tempo, constitui-se como tarefa, evidenciando obrigação positiva de atuação.

Fazendo mais uma vez alusão à Rosenvald (2010, p. 38):

\begin{abstract}
A dignidade da pessoa humana é, simultaneamente, direito objetivo e subjetivo. Isto é, longe de apenas propiciar à pessoa o direito ao respeito e imunidade em face de qualquer atentado à sua personalidade, a dignidade reclama por patamares mínimos de existência, de acordo com a exigência de justiça social como fim da ordem econômica.
\end{abstract}

A dignidade da pessoa humana deve ser o vetor interpretativo das demais normas jurídicas do sistema, pois a Constituição não é axiologicamente neutra, sendo vedado ao interprete o recurso às suas convicções pessoais e relativas para a emissão de juízos de valor.

Uma compreensão sólida e constitucionalmente adequada da noção de dignidade constitui pressuposto para uma análise séria e frutífera de qualquer problema concreto.

O direito a um patrimônio mínimo, instituto este defendido por Fachin (2006, p. 16) em sua tese de doutorado, segundo consubstanciada "na existência de uma garantia patrimonial mínima inerente a toda pessoa humana, integrante da respectiva esfera jurídica individual ao lado dos atributos pertinentes à própria condição humana”.

A dignidade da pessoa humana está na origem dos direitos materialmente fundamentais e representa o núcleo essencial de cada um deles, assim os individuais como os políticos e os sociais. Procura-se estabelecer os contornos de uma objetividade possível, apta a prover a racionalidade e controlabilidade à sua utilização nas decisões judiciais, $\mathrm{O}$ princípio da dignidade humana identifica um espaço de integridade a ser assegurado. A dignidade relaciona-se tanto com a liberdade e valores do espírito quanto com as condições materiais de subsistência. No seu âmbito se inclui a proteção do mínimo existencial, locução que identifica o conjunto de bens e utilidades básicas para a subsistência física e indispensável ao desfrute dos direitos em geral.

A Declaração Universal dos Direitos Humanos já prevê em seu preâmbulo a dignidade da pessoa humana, afirmando: 
Considerando que o reconhecimento da dignidade inerente a todos os membros da família humana e de seus direitos iguais e inalienáveis é o fundamento da liberdade, da justiça e da paz no mundo.

Nada obstante a relativa indeterminação do conceito de dignidade humana, há consenso de que seu núcleo central deverão estar a rejeição às penas corporais, à fome compulsória e ao afastamento arbitrário da família (BARROSO, 2003, p. 39). O princípio da dignidade da pessoa humana identifica um espaço de integridade moral a ser assegurado a todas as pessoas por sua só existência no mundo. Relaciona-se tanto com a liberdade e valores de espírito como as condições materiais de subsistência.

O princípio deve transitar de uma dimensão ética e abstrata para as motivações racionais e fundamentadas das decisões judiciais.

O sistema constitucional é formado por normas, e recentemente consolidou-se a existência destas normas como uma categoria geral, um gênero o qual se desdobra em duas espécies, princípios e regras.

As constituições em tempos remotos eram entendidas apenas como documentos de divisão e estruturação do poder. A função de traçar valores para o ordenamento jurídico surgiu após a segunda guerra mundial.

Mas mesmo assim, nosso judiciário tem se conduzido com grande dificuldade quanto à aplicação direta desse princípio ao caso prático.

Os princípios, ao expressar valores ou indicar fins a serem alcançados pelo Estado e pela sociedade, irradiam-se pelo sistema, interagem entre si. A eficácia é um atributo associado às normas e consiste na consequência jurídica que deve resultar de sua observância, podendo ser exigida judicialmente se necessário. A percepção de que também aos princípios constitucionais deve ser reconhecida eficácia jurídica é fenômeno relativamente recente. É a chamada eficácia positiva ou simétrica, reconhecendo àquele beneficiado pela norma ou simplesmente àquele que deveria ser atingido pela realização de seus efeitos, direito subjetivo a esses efeitos, de modo que seja possível obter a tutela específica da situação contemplada no texto legal. A eficácia positiva ou simétrica pretende assegurar ao interessado a possibilidade de exigi-los diretamente, na via judicial se necessário.

Assim, a pessoa humana - e não mais o sujeito de direito neutro e abstrato -, qualificada na concreta relação jurídica em que se insere, de acordo com o valor social de sua atividade, e protegida pelo ordenamento segundo o grau de vulnerabilidade que apresenta, em 
qualquer situação que reclame tutela, torna-se a categoria central do direito privado, redesenhado pelos valores constitucionais.

\section{CONCLUSÃO}

Em conclusão, pode-se afirmar que a tutela dos direitos humanos na atividade econômica e, mais genericamente, nas relações de direito privado, consolida-se na interpretação dos espaços público e privado, fazendo-se a cada dia mais urgente, na medida em que os avanços tecnológicos e ampliação dos mercados tendem a "despersonificar" o indivíduo, aniquilando conquistas sociais e fomentando o predomínio da perversa lógica econômica.

Esta renovação dos institutos privados à procura da equidade, da dignidade da pessoa, da boa-fé e da segurança nas relações vai aqui ser chamada de socialização das relações. Nessa linha, é imperativa uma nova compreensão do Direito Civil a partir dos novos valores e da legalidade constitucional. Estamos no tempo de estabelecimento de relações solidárias entre as pessoas, que devem preservar e até mesmo fomentar a dignidade da pessoa humana.

Hoje o direito preocupa-se muito mais com as partes da relação jurídica, na busca de tutelar a dignidade desses sujeitos, que com seu objeto, conforme os efeitos da personificação do direito civil.

Cabe ao jurista, portanto, diante de tal quadro, procurar o estabelecimento de uma ordem jurídica compatível com a evolução da sociedade, buscando a proteção do hipossuficiente, com o sentimento de equidade, a fim de que se possa alcançar o restabelecimento do equilíbrio real nas relações contratuais, à luz de nossa Constituição Federal.

\section{REFERÊNCIAS}

BARROSO, Luís Roberto. Curso de direito constitucional contemporâneo - os conceitos fundamentais e a construção do novo modelo. São Paulo: Saraiva, 2009. 
Neoconstitucionalismo e a constitucionalização do direito (O triunfo tardio do direito constitucional no Brasil). In. Revista de direito constitucional e internacional, $\mathrm{n}^{\circ} 58$. São Paulo: Revista dos Tribunais, 2007.

; DE BARCELlOS, Ana Paula. O começo da história. A nova interpretação constitucional e o papel dos princípios no direito brasileiro. In. Revistada da EMERJ, vol. 06, no 23. Rio de Janeiro, 2003.

BRANCO, Paulo Gustavo Gonet. Aspectos de teoria geral dos direitos fundamentais. In: Hermenêutica Constitucional e Direitos Fundamentais. $2^{\mathrm{a}}$ parte. $1^{\mathrm{a}}$ edição, $2^{\mathrm{a}}$ tiragem. Ed. Brasília Jurídica. Instituto Brasiliense de Direito Público: Brasília, 2002.

CANOTILHO, J.J. Gomes. Direito constitucional e teoria da constituição. $7^{\text {a }}$ edição.Coimbra: Editora Livraria Almedina, 2003.

FACHIN, Luiz Edson. Estatuto do patrimônio mínimo. 2a edição. Rio de Janeiro: Renovar, 2006.

GODOY, Cláudio Luiz Bueno de. Função social do contrato. $2^{\text {a }}$ edição. São Paulo: Saraiva, 2007.

LAFER, Celso. A reconstrução dos direitos humanos: um diálogo com o pensamento de

Dannah Arendt. São Paulo: Companhia das Letras, 1988.

LISBOA, Roberto Senise. Contratos difusos e coletivos. $3^{\text {a }}$ edição. São Paulo: Editora Revista dos Tribunais, 2007.

LOPES, Ana Maria D‘Ávila. Democracia hoje. Para uma leitura crítica dos direitos fundamentais. Passo Fundo: Universidade de Passo Fundo, 2001

PEREIRA, Caio Mario da Silva. Instituições de direito civil, vol $1 .{ }^{a}$ edição. Rio de Janeiro: Forense, 2004.

PIOVESAN, Flávia. A proteção dos direitos humanos no sistema constitucional brasileiro. In, Revista de direito constitucional e internacional, v. 45, 2003.

REALE, Miguel. Filosofia do Direito. 17 ed. São Paulo: Saraiva, 1996.

ROSENVALD, Nelson; de FARIAS, Cristiano Chaves. Direito civil- teoria geral. $8^{\mathrm{a}}$ edição. Rio de Janeiro: Lúmen Júris, 2010.

SARLET, Ingo Wolfgang. A eficácia dos direitos fundamentais. 6 ed., Porto Alegre : Livraria do Advogado, 2006.

SARMENTO, Daniel. Direitos fundamentais e relações privadas. $2^{\mathrm{a}}$ edição. Rio de Janeiro: Lúmen Júris, 2006. 
TAVARES, André Ramos. Curso de direito constitucional. $4^{\text {a }}$ edição. São Paulo: Saraiva, 2006.

TEPEDINO, Gustavo. Temas de direito civil, Tomo I. Rio de Janeiro: Renovar, 2006. 